Factors influencing elective science students' perception of their Biology classroom environment in low and high academic achieving schools in the Central Region of Ghana

Otami, Deodat Charles $\bowtie$
University of Cape Coast, Ghana (deodatcharlesotami@yahoo.com)

Ampiah, Joseph Ghartey

University of Cape Coast, Ghana (jgampiah@yahoo.com)

Anthony-Krueger, Christian

University of Cape Coast, Ghana (kruegertony@yahoo.com)

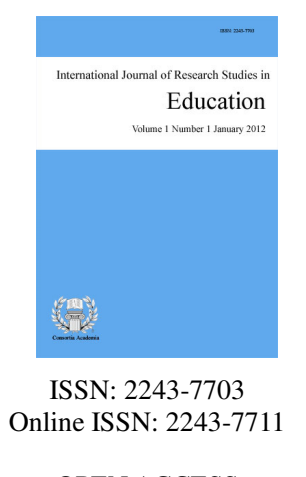

OPEN ACCESS

\title{
Abstract
}

The study investigated factors influencing elective science students' perception of their Biology classroom environment in low and high academic achieving senior secondary schools in the Central Region of Ghana. The cross-sectional survey research design was adopted. Participants were 356 third-year elective science students, selection through a multi-stage sampling technique. Data were obtained using the Biology Classroom Environment Questionnaire (BCEQ). This was after the senior secondary schools that offer elective science program had been categorized into low and high academic achieving schools based on their performance in Senior Secondary School Certificate Examination/West Africa Senior Secondary School Examinations for five years. Two third-year intact classes were randomly selected from four schools under each category. Data analysis includes Factor and Item Analyses, and Multivariate Analysis of Variance. The findings revealed that four factors influence elective science students' perception of their Biology classroom environment. The findings further suggested that elective science students in both school categories had a low perception of their Biology classroom environment but significantly different in favor of the elective science students in low academic achieving schools in teacher support, cooperation, and equity. Implications of the study are discussed and recommendations given.

Keywords: Biology; classroom environment; elective science students; perception 


\section{Factors influencing elective science students' perception of their Biology classroom environment in low and high academic achieving schools in the Central Region of Ghana}

\section{Introduction}

The concept of classroom environment as applied to educational setting is viewed as a place where learners and teachers interact with each other and use a variety of tools and information resources in their pursuit of learning activities (Fout \& Myers, 1998; Mucherah, 2008). Although classroom environment is a subtle concept, remarkable progress has been made over the last five decades to conceptualize, assess, and research into it (Fraser, 2001). Classrooms are specific places in schools where results of education, that is, understanding and application of knowledge in our lives are expected to be achieved, and these places have lots of influence on students in respect of achieving these noble goals (Fraser, 1981). Creating favorable classroom environments should therefore be of great importance to science educators since evidence suggests that classroom environment influences students' learning. Perception as noted by Teh (as cited in Ampiah, 2006) influences human behavior in science related issues and this has been found to exist worldwide. It is important therefore to investigate the way students perceive their Biology classroom environment because of its effect on their achievement in the subject as has been reported in the literature (Taylor, 2004).

Even though these reasons have been identified in the literature as influencing Senior Secondary School (SSS) science students' achievements in Biology, studies by Mucherah (2008) and Myint \& Goh (2001) have reported that classroom environments perceived by students as being conducive tend to enhance the development of positive attitude towards a subject matter and hence, better achievement in it. However, most classroom environment studies have been carried out in developed countries like United States of America (USA), Australia, New Zealand and some countries in Asia such as Taiwan, Turkey, and Singapore (Fraser, 2000). There is very little reported on how SSS science students perceive their Biology classroom environment in Africa (Mucherah, 2008). Though a study on SSS science students' perception of their science laboratory learning environment have been reported in Ghana (Ampiah, 2006), little is known about how Ghanaian SSS elective science students perceive their Biology classroom environments. It is, therefore, important that a study is carried out in Ghana to find out how SSS elective science students' perceive their Biology classroom environments and what factors, if any, influence their Biology classroom environment. Since classroom environment which are found to be conducive tend to enhance the development of positive attitude towards Biology and thereby leading to higher achievement in it (Fraser \& Fisher, 1998; Myint \& Goh, 2001; Chui-Seng, 2004; Mucherah, 2008).

In Kenya, a study conducted has revealed that achievements in national school examinations were influenced by the kind of school one attended, and the availability of resources in the school (Mucherah, 2008). This is not very different in Ghana, where achievements of SSS elective science students in Biology appear to be determined by the kind of school one attends. This is because results released by the West Africa Examinations Council (WAEC) in Biology have consistently indicated that, schools that are well equipped in terms of science laboratories, textbooks, and qualified science teachers tend to produce better results while poorly equipped schools perform poorly in the subject (Addae-Mensah, 2003). While some authorities are of the view that schools with better achievements in Biology have good infrastructure in terms of science laboratories, science textbooks, adequate number of qualified science teachers and many other reasons. It has also been noted that some schools with all these facilities do perform poorly in the subject in WAEC examinations (Addae-Mensah, 2003). The question that one needs to ask is that, are these disparities in achievements in Biology coming from the differences in Biology classroom environments in the schools? What factors, if any influence the elective science students' perception of their Biology classroom environment?

According to Mucherah (2008) much has not been reported on these important aspects of science education 
Factors influencing elective science students' perception of Biology classroom in Ghana

in Africa, hence the need to explore if any what factors influence Ghanaian students' perception of their Biology classroom environment. In spite of the underachievement of SSS elective science students in Biology as indicated by WAEC examinations results, some SSS in Central Region have consistently obtained good pass rates in the sciences including Biology in the WAEC organized examinations (WAEC, 2002, 2003, 2004, \& 2005). The question that needs to be asked is, why are some schools performing better than others? Could it be that the SSS that obtain better passes in the subject have better Biology classroom environments? If so what factors if any influence elective science students' perception of their Biology classroom environment in schools whose achievement in Biology is better and those are poor.

\subsection{Research questions}

This study sought to explore factors, if any, underlying elective science students' perception of their Biology classroom environment and to find out whether elective science students from SSS whose achievement in Biology are low and those whose achievement in Biology are high perceive their Biology classroom environments differently. The following research questions were therefore formulated to guide the study.

1. What underlying factors affect elective science students' perception of their Biology classroom environment?

2. What is the difference between the perception of elective science students' in low and high academic achieving schools of their Biology classroom environment?

\section{Methodology}

\subsection{Participants}

This study is a cross-sectional survey carried out among senior secondary school elective science students in the Central Region of Ghana. A multi-stage sampling technique was employed in the study. A total of 23 SSS that offered elective science program (Physics, Chemistry, and Biology) in 2007/2008 academic year out of the 50 public SSS in the Region were categorized into high and low academic achieving schools. This was based on the general ranking of the schools in Senior Secondary School Certificate Examination (SSSCE)/West Africa Secondary School Certificate Examination (WASSCE) in 2002, 2003, 2004, 2005, 2006 and 2007. The general performances of these years' rankings were used because the headmasters of the schools were not willing to release the performance of their schools in Biology for the study. Furthermore, WAEC could not also provide the results of the individual schools in Biology due to technical problems, but could only provide the general performance of the schools in SSSCE/WASSCE in the mentioned years. In categorizing the senior secondary schools those that offer elective science program that fell within the top 50 schools out of the 474 public senior secondary schools nationwide in 2002, 2003, 2004, 2005, 2006 and 2007 were categorized as high academic achieving schools. However, schools that fell within the last 50 in the performance rankings of the years stated were also categorized as being low academic achieving schools. Base on this categorization, six and eight senior secondary schools fell into the high and low achieving schools respectively.

Four senior secondary schools under each stratum were randomly selected using computer generated random numbers. This was done to give the schools in each stratum an equal chance of being selected for the study. From these four schools, elective science students in two intact classes were randomly selected using computer generated random numbers from schools that had more than two streams of classes whereas those with two or less streams of classes had those classes automatically selected to be part of the study. Schools that fell within the low academic achieving school category had between one or two streams of science classes with an average class size of 35 students whereas those within the high academic achieving school category mostly had between three and four streams of science classes with an average class size of 30 . 
Otami, D. C., Ampiah, J. G., \& Anthony-Krueger, C.

In all, 356 elective science students from the different school categories participated in the study. A breakdown of background information of the respondents based on school type is given in Table 1 .

Table 1

Participants demography $(N=356)$

\begin{tabular}{ccccccc}
\hline $\begin{array}{c}\text { School } \\
\text { Types }\end{array}$ & $n$ & $\%$ & $n$ & $\%$ & $\begin{array}{l}\text { Mean } \\
\text { Age }\end{array}$ & $\begin{array}{l}\text { Total } \\
n\end{array}$ \\
LAS & & Males & & Females & & \\
HAS & 85 & 61.2 & 54 & 38.9 & 17.9 & 139 \\
& 106 & 48.9 & 111 & 51.2 & 17.2 & 217 \\
\hline
\end{tabular}

Note. LAS = Low Achieving School, HAS = High Achieving School. Age is in years

One hundred and thirty nine students comprising $38.9 \%$ females and $61.2 \%$ male with a mean age of 17.9 years and a standard deviation of 0.72 years were from the low academic achieving schools. For the high academic achieving schools, there were 217 elective science students comprising $51.2 \%$ females and $48.9 \%$ males with a mean age of 17.2 years and a standard deviation of 0.84 years.

\subsection{Research instrument}

Elective science students' perception of their Biology classroom environment was measured using a 40-item Biology Classroom Environment Questionnaire (BCEQ) (Otami, 2009). In constructing the BCEQ, "What Is Happening In This Class?" (WIHIC) instrument developed by Fraser, McRobbie and Fisher (1996) to measure senior secondary school students' perception of their science classroom environment served as a guide. The various components of the WIHIC developed by Fraser, McRobbie and Fisher reported Cronbach reliabilities as follows: Students Cohesiveness $=0.92$; Teacher support $=0.97$; Involvement $=0.89$; Cooperation $=0.88$; and Equity $=0.931$.

In developing the BCEQ for the study, it was assumed that the students' perception of their Biology classroom was multidimensional. Five scales that were considered to be appropriate for the Biology Classroom Environment Questionnaire (BCEQ) were student cohesiveness, teacher support, involvement, cooperation and equity. The initial version of the BCEQ contained 40-items altogether. Each item was scored on a five-point Likert-type scale format (5-Very often, 4-Often, 3-Sometimes, 2-Seldom, 1-Almost never). The higher the scale score, the more a student demonstrated that particular scale of perception.

\subsection{Research process}

In each of the eight senior secondary schools, questionnaires were distributed to students during their Biology lessons. Students were allowed enough time to complete the questionnaire. The questionnaires were coded to indicate the school type and age of the respondents. The questionnaires were collected the same day after completion.

\subsection{Data analysis}

Data were subjected to series of item analyses in order to identify items whose removal would enhance the internal consistency of the instrument. A series of factor analysis were conducted using Statistical Package for Social Sciences (SPSS) version 15 for the data processing and analysis on the BCEQ using principal axis factor analysis technique to determine the factors underlying elective science students' perception of their Biology 
classroom environment. Differences between perception of the Biology classroom environment held by students in the different school types (low and high academic achieving schools) were analyzed using one-way multivariate analysis of variance (MANOVA). The corresponding one-way analysis of variance (ANOVA) with school-type as the independent variable was examined for each of the BCEQ scales individually as a follow up test to the MANOVA to determine whether a significant difference exists between the school-type on each scale.

\section{Results and Discussions}

\subsection{Factor analysis}

In refining and validating the BCEQ, a series of factor analysis were conducted using Statistical Package for Social Sciences (SPSS). Prior to performing the principal component analysis the suitability of the data for factor analysis was assessed. Inspection of the correlation matrix revealed the presence of many coefficients of 0.3 and above. The Kaiser-Meyer-Oklin value was 0.89, exceeding the recommended value of 0.60 Kaiser (as cited in Pallant, 2007) and the Barlett's test of sphericity reached statistically significance, supporting the factorability of the correction matrix. The 40 items on the BCEQ were analyzed using principle axis factor analysis. Factor analysis gave four factors with eigenvalues greater than one to be rotated. The scree plot which is shown in Figure 1 confirmed that BCEQ consisted of more than one linear scale and hence the assumptions that more than one scale influence elective science students' perception of their Biology classroom environment was upheld.

Although the scree plot suggests a final solution with three principal components, there were four eigenvalues greater than one. The rotation of these five components using varimax and the resultant interpretation seem appropriate. Factor analysis led to the deletion of 10 items (Items 2, 3, 10, 14, 17, 19, 20, 21, 28, and 40) from the BCEQ; the reason being that these items loaded significantly on more than one scale. Involvement did not emerge as factor during the validation of the BCEQ and items that belonged to that scale were removed. This is not surprising, as many studies in the past have recorded low levels of involvement (Mucherah, 2008; Taylor, 2004; Aldridge, Fraser, \& Fisher, 2000).

\section{Scree Plot}

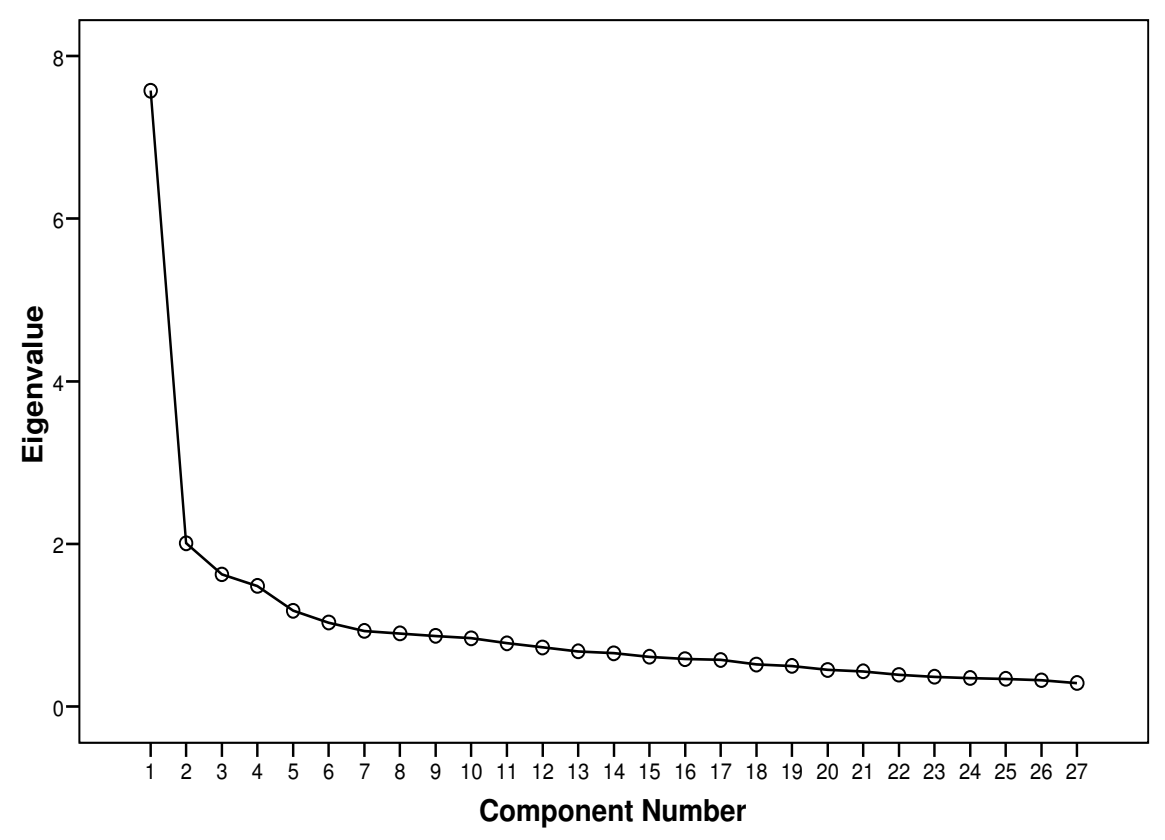

Figure 1. Scree plot of eigenvalues greater than one of Biology classroom environment questionnaire 
Furthermore, student cohesiveness scale seems to overlap with the teacher support scale and so there was very little to differentiate between student cohesiveness and teacher support looking at the items that constituted the two scales. When factor and item analyses were conducted on the remaining items, four scales were finally settled on. To this end, four factors with eigenvalues greater than one were rotated using a varimax rotation procedure.

Table 2 shows the loadings obtained as a result of factor analysis.

Table 2

Rotated component matrix showing factor loading and amount of variance explained for the final Biology classroom environment instrument

\begin{tabular}{|c|c|c|c|c|}
\hline \multirow[b]{2}{*}{ Item number } & \multicolumn{4}{|c|}{ Factors } \\
\hline & 1 & 2 & 3 & 4 \\
\hline 34 & 0.676 & & & \\
\hline 38 & 0.639 & & & \\
\hline 33 & 0.630 & & & \\
\hline 16 & 0.618 & & & \\
\hline 37 & 0.607 & & & \\
\hline 39 & 0.606 & & & \\
\hline 25 & & 0.486 & & \\
\hline 23 & & 0.470 & & \\
\hline 26 & & 0.408 & & \\
\hline 32 & & 0.363 & & \\
\hline 8 & & 0.310 & & \\
\hline 29 & & 0.309 & & \\
\hline 27 & & 0.307 & & \\
\hline 18 & & & 0.506 & \\
\hline 1 & & & 0.419 & \\
\hline 7 & & & 0.319 & \\
\hline 6 & & & 0.372 & \\
\hline 11 & & & & 0.511 \\
\hline 12 & & & & 0.458 \\
\hline 9 & & & & 0.426 \\
\hline 5 & & & & 0.312 \\
\hline 4 & & & & 0.303 \\
\hline$\%$ of Variance explained & 28.1 & 7.4 & 6.0 & 5.5 \\
\hline Eigenvalues & 7.6 & 2.0 & 1.6 & 1.5 \\
\hline
\end{tabular}

Note. Factor loading less than 0.3 have been omitted.

Factor 1 = Equity, Factor 2 = Cooperation, Factor 3 = Student Cohesiveness, Factor 4 =Teacher Support 
Factors influencing elective science students' perception of Biology classroom in Ghana

The rotated solution as shown in Table 2 reported the following four interpretative factors: equity, cooperation, student cohesiveness and teacher support. With the removal of 18 items from the 40 item-BCEQ, 22 items and four-factor solution were settled upon as the optimal structure for the final version of the BCEQ. Each of the remaining items had a factor loading of 0.30 and above which according to Fraser, McRobbie, and Giddings, (1998) is acceptable when using individual students as a unit of analysis. The percentage of total variance explained by the four factors is quite large $(47.0 \%)$ using the individual mean scores as the unit of analysis. The eigenvalues indicate a slight dominant first principal component (equity). The amount of variance between the elective science students explained by the first factor is $28.1 \%$. The results of the factor loading as shown in Table 2 indicate that the first component ranged from 0.606 to 0.678 . This means that, all the elective science students in both school types had a high and positive correlation with the first component. The inter-correlations among equity were the highest among the four factors. This component was interpreted to mean the extent to which students were treated equally. The four factors that emerged in the study and their interpretations are given in Table 3.

Table 3

Factors and their descriptions of the final BCEQ

Scales Description

Equity

Extent to which students are treated equally

Cooperation

Extent to which students cooperate rather than compete with one another on learning task

Student cohesiveness Extent to which students know, help and are friendly toward each other

Teacher support Extent to which the teacher is interested in the students, while displaying characteristics of helpfulness, trustfulness, and friendliness

Unlike the WIHIC developed by Fraser, McRobbie, and Fisher (1996) which served as a guide for the development of BCEQ, involvement was not part of the final BCEQ. Item analyses procedures were conducted on the final 22 items of the BCEQ. Table 4 reports Cronbach alpha coefficients for the four BCEQ scales using individual science students as the unit of analysis. Coefficients ranging from 0.66 to 0.81 exceeded the threshold value of 0.60 given by Nunnally (as cited in Ampiah, 2006) as an acceptable reliability coefficient for research purposes. In summary, the study identified four factors that underlie elective science students' perception of their Biology classroom environment. These were equity, cooperation, student cohesiveness, and teacher support. A series of item and factor analyses on the BCEQ led to the emergence of a refined version of the BCEQ which was found to report satisfactory internal consistency and factorial validity. This final version was then used to explore the questions that were formulated to guide the study.

Table 4

Reliability coefficients for the scales of the final BCEQ

\begin{tabular}{lc}
\hline \multicolumn{1}{c}{ Scale } & Alpha Reliability \\
\hline Equity & 0.81 \\
Cooperation & 0.79 \\
Student cohesiveness & 0.66 \\
Teacher support & 0.71 \\
\hline
\end{tabular}


Otami, D. C., Ampiah, J. G., \& Anthony-Krueger, C.

3.2 The difference between the Perception of elective science students' in low and high academic achieving

schools of their Biology Classroom environment

The question what is the difference between elective science students' perception of their Biology classroom environment in low and high academic achieving schools was tested. Mean scores of responses by students in both school types showed that the students had a low perception of the Biology classroom environment. Table 5 indicates the mean and the standard deviation scores of the responses provided by students in both school types on the four factors that influence their perception of their Biology classroom environment.

Table 5

Mean and Standard Deviation (SD) Scores for LAS and HAS on Biology Classroom Environment (BCE) Subscales

\begin{tabular}{llllll}
\hline \multirow{2}{*}{$\begin{array}{l}\text { BCEQ } \\
\text { Sub-scales }\end{array}$} & \multicolumn{3}{c}{ School type } & \multicolumn{2}{c}{ HAS } \\
\cline { 2 - 3 } \cline { 5 - 6 } & Mean & $S D$ & & Mean & $S D$ \\
\hline Equity & 2.2 & 0.8 & & 1.9 & 0.8 \\
Cooperation & 2.5 & 0.7 & & 1.9 & 0.6 \\
Student cohesiveness & 2.4 & 0.7 & & 2.2 & 0.7 \\
Teacher support & 2.2 & 0.8 & & 1.9 & 0.8 \\
\hline
\end{tabular}

Note. $n=139(\mathrm{LAS})=$ low academic achieving schools; Average Mean Score $=3$

$n=217($ HAS $)=$ high academic achieving schools

School-type related difference in perception of Biology classroom environment was investigated using one-way Multivariate Analysis of Variance (MANOVA). The MANOVA test reported that Wilks' Lambda $(\lambda)$ value of 0.81 was statistically significant $F(10,704)=7.76, p<0.001$; partial eta squared $=0.10$, indicating that the population mean scores on the four sub scales of Biology classroom environment are the same for elective science students in low and high academic achieving schools. This means that there is statistically significant difference between the perception of elective science students in low and high academic achieving schools across the four subscales of their Biology classroom environment. A corresponding Analysis of Variance (ANOVA) with school types as an independent variable was conducted for each of the Biology classroom environment sub scales as a follow-up test to the MANOVA as shown in Table 6.

\section{Table 6}

Results of ANOVA as a follow-up to the one-way MANOVA on the four sub-scales of the BCEQ

\begin{tabular}{lllll}
\hline BCE Sub-scales & Mean $^{2}$ & $F$ & $P$-value & Partial eta square \\
\hline Equity & 5.5 & 8.4 & 0.001 & 0.05 \\
Cooperation & 11.8 & 27.9 & 0.001 & 0.14 \\
Student cohesiveness & 1.6 & 4.1 & 0.018 & 0.02 \\
Teacher support & 4.1 & 6.6 & 0.002 & 0.04 \\
\hline
\end{tabular}

Note. Bonferroni adjusted significant at $p<0.05$

This was to determine the sub-scale(s) which was/were contributing to the differences between the elective sciences students' perception of their Biology classroom environment in both school types. Sub scales of Biology classroom environment that were statistically significant using a Bonferroni adjusted alpha level of 0.005 , were teacher support: $F(2,365)=6.6, p=0.002$, partial eta squared $=0.036$; cooperation: $F(2,356)=27.88$, $p<0.001$, partial eta square $=0.14$; and equity: $F(2,356)=8.39, p<0.001$; partial eta squared $=0.05$. The partial 
Factors influencing elective science students' perception of Biology classroom in Ghana

eta squared recorded for the three sub scales indicate that three out of the five sub scales; teacher support, cooperation and equity accounts for the variances in elective science students' in low and high academic achieving schools perception of their Biology classroom environment.

An inspection of the mean scores as presented in Table 5 indicates that elective science students in low academic achieving schools had a slightly high levels of teacher support $(M=2.2, S D=0.8)$ than elective science students in high academic achieving schools $(M=1.9, S D=0.8)$. A further inspection of mean scores as reported in Table 5 reveals that elective science students in low academic achieving schools had a slightly high level of cooperation $(M=2.5, S D=0.7)$ than elective science students in high academic achieving schools $(M=$ 1.9, $S D=0.6$ ). Similarly, mean scores as reported in Table 4 indicate that elective science students in low academic achieving schools again had a slightly high level of equity: $(M=2.2, S D=0.8)$ than their counterparts in high academic achieving schools $(M=1.9, S D=0.8)$. This result is not surprising since students in high academic achieving schools may think that they can read Biology on their own with little or no help from their teachers and peers. Again teachers in the low academic achieving schools may give their students more attention since they may seem weaker in Biology than their counterparts in high academic achieving schools.

In summary the study identified four factors that underlie students' perception of their Biology classroom environment. These are equity, cooperation, student cohesiveness and teacher support. This means that more than one factor influence students' perception of their Biology classroom environment (Fisher, Mcrobbie, \& Fisher, 1996). This confirms findings from other studies in the literature (Fraser \& Fisher, 1998; Taylor, 2004; \& Mucherah, 2008). The results also show that students' general perception of their Biology classroom environments in both low and high academic achieving schools were low but significantly different in favor of elective science students in low academic achieving schools. Elective science students' in low academic achieving schools expressed significantly more equity, cooperation and teacher support than their counterparts in high academic achieving schools. Equity and Cooperation dominated elective science students' perception of their Biology classroom environment. The difference in perception of the students reflected the desire of both students and Biology teachers to support each other.

\section{Conclusions}

\subsection{Implications for teaching}

The findings of this study provide evidence that elective science students' irrespective of the school type have a low perception of their Biology classroom environments and Biology teachers need to employ strategies in their teaching that will enable students form a good impression of their Biology classroom environment. The findings that equity, cooperation and students cohesiveness are the factors that distinguished between elective science students' perception of their Biology classroom environments in low and high academic achieving schools meant that, to improve Biology classroom environment these factors need to be give the utmost attention.

\subsection{Recommendations}

The field of classroom environment provides a number of valuable ideas and techniques for inclusion in evaluation of teaching, however, little progress have been made in incorporating these ideas into teaching program. It is, therefore, recommended that classroom teachers use assessment of classroom environment to facilitate practical improvements in classrooms.

\section{References:}

Abdul-Mumuni, I. (1995). Teachers' views about issues in Biology education in the Northern Region. Unpublished PGDE Project Submitted to University of Cape Coast. 
Otami, D. C., Ampiah, J. G., \& Anthony-Krueger, C.

Addae-Mensah, I. (2003). Education in Ghana: A tool for social mobility or stratification. The J. B. Danquah Memorial Lectures, British Council Hall, Accra (April, 2003).

Aldridge, J. M., Fraser, B. J., \& Fisher, D. L. (2002). Outcomes based technology-rich science learning environments: Assessing students' perceptions. Paper Presented at the Annual Meeting of the National Association for Research in Science Teaching, New Orleans, LA (April, 2002).

Ampiah, J. G. (2006). Students' psychosocial perception of science laboratory environments in Ghanaian senior secondary schools. Ife Psychologia, 2, 136-151.

Anamuah-Mensah, J. (2007). Relevant data collected for PRACTICAL project plan. Paper Presented at the PRACTICAL workshop.NPT/PRACTICAL Project, Elmina (18-20 December, 2007).

Anthony-Krueger, C. (2007). A study of factors militating against laboratory practical work in Biology among Ghanaian senior secondary school students. Journal of Science and Mathematics Education, 3(1), 44-54.

Chui-Seng, Y. B. (2004). Secondary science students' perceptions of their learning environment and its association with achievement in Biology. Learning Environment Research, 7, 134-146.

Fisher, D. L., \& Fraser, B. J. (1998).Research on classroom and school climate. In B. J. Fraser \& K. G. Tobin (Eds), International Handbook of Science Education (pp. 527-564). Dordrecht Netherlands: Kluwer Academic Publishers.

Fout, J. T., \& Myers, R. E. (1998). Classroom environment and middle school students' views of science. Journal of Educational Research, 85, 356-361. doi:10.1080/00220671.1992.9941138 <http://dx.doi.org/10.1080/00220671.1992.9941138>

Fraser, B. J. (2001). Twenty thousand hours. Learning Environment Research, 4, 1-5. doi:10.1023/A:1011406709483 <http://dx.doi.org/10.1023/A:1011406709483>

Fraser, B. J. (1981). Validity and use of classroom environment instruments. Journal of Classroom Interaction, 26(2), 5-11.

Fraser, B. J., McRobbie, C. J., \& Fisher, D. L. (1996). Development, validation and use of personal and class forms of a new classroom environment instrument. Paper presented at the Annual Meeting of the American Educational Research Association, Chicago (13-17 May, 1996).

Fraser, B. J., McRobbie, C. J., \& Giddling, G. J. (1993). Development and cross-national validation of laboratory classroom environment instrument for senior high School science students. Science Education, 77(1), 1-24. doi:10.1002/sce.3730770102 <http://dx.doi.org/10.1002/sce.3730770102>

Lakpini, M. (2007). A study of senior secondary school students' misconceptions in genetics implication for teaching and learning Biology. Journal of Science and Mathematics Education, 3(1), 32-43.

Mucherah, W. (2008). Classroom climate and students, goal structure in high school Biology classrooms in Kenya. Learning Environment Research, 11, 63-81. doi:10.1007/s10984-007-9036-x $<$ http://dx.doi.org/10.1007/s10984-007-9036-x>

Myint, S. K., \& Goh, S. C. (2001). Investigation of tertiary classroom learning environment in Singapore. Paper Presented at the International Educational Conference, Australian Association for Educational Research (AARE), University of Notre Dame, Fremantle, Western Australia (2-6 December 2001).

Otami, D. C. (2009). An investigation into senior secondary school elective science students' perception of their Biology classroom environment and their Attitude towards Biology. Unpublished masteral thesis, University of Cape Coast, Ghana.

Pallant, J. (2007). SPSS Survival Manual, a step by step guide to data analysis using SPSS version 15 (2nd ed). Glasgow: Bell \& Bain Ltd.

Shaibu, A. A. M., \& Olarewaju, R. R. (2007). Perception of difficult Biology concepts among senior secondary school students in Kaduna, Nigeria. Journal of Science and Mathematics Education, 3(1), 124-133.

Taylor, B. J. (2004). Influence of classroom environment on high school students' Mathematics anxiety and attitudes. Unpublished doctoral dissertation, Curtin University of Technology, Australia. 
Appendix A

\section{BIOLOGY CLASSROOM ENVIRONMENT QUESTIONNAIRE}

\section{INTRODUCTION}

This questionnaire contains statements about practices which could take place in the biology class. You will be asked how often each practice takes place in the biology class. There are no 'correct' or 'wrong' answers. Your responses will be used for research purposes. Confidentiality of your response will be assured. Think about how well each statements. If you change your mind about any response just cross it out and tick another one. Some statements in this questionnaire are fairly similar to other statements. Do not worry about it. Please make a tick $(\sqrt{ })$ in the box against your response.

Thanks for your maximum cooperation.

\section{SECTION A}

BIOGRAPHIC DATA

Sex: Male [ ] Female [ ]

Age:

School's Name:

\section{SECTION B}

How often do the statements describe practices that take place in your biology classroom?

\begin{tabular}{|c|c|c|c|c|c|}
\hline Items & Very often & Often & Sometimes & Seldom & Almost Never \\
\hline \multicolumn{6}{|l|}{ Equity } \\
\hline $\begin{array}{l}\text { I get the same amount of help from my biology } \\
\text { teacher as the students in the class. }\end{array}$ & & & & & \\
\hline $\begin{array}{l}\text { The biology teacher trusts me to get certain } \\
\text { amount of work done as other students in the } \\
\text { biology class. }\end{array}$ & & & & & \\
\hline $\begin{array}{l}\text { My biology teacher gives as much attention to } \\
\text { my questions as do other students' questions. }\end{array}$ & & & & & \\
\hline $\begin{array}{l}\text { My biology teacher asks me questions to find out } \\
\text { if I understand the lesson. }\end{array}$ & & & & & \\
\hline $\begin{array}{l}\text { I receive the same encouragement from my } \\
\text { biology teacher as other students do. }\end{array}$ & & & & & \\
\hline $\begin{array}{l}\text { My work in biology receives as much praise as } \\
\text { other students' work in the biology class. }\end{array}$ & & & & & \\
\hline
\end{tabular}


Otami, D. C., Ampiah, J. G., \& Anthony-Krueger, C.

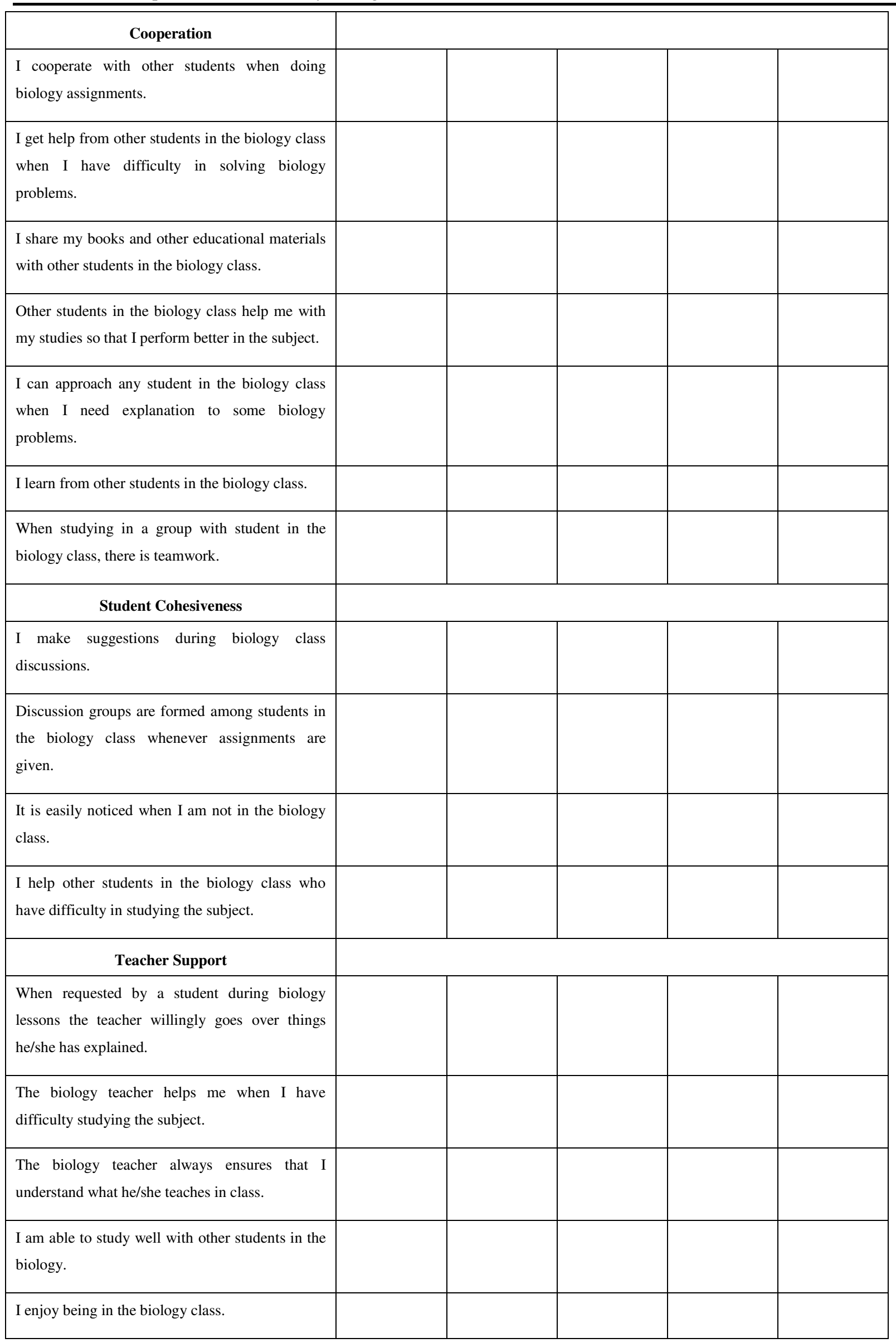

